\title{
Avaliação de Jogos Educativos: Uma Abordagem no Ensino de Matemática
}

\author{
Wilk Oliveira dos Santos ${ }^{12}$, Sebastião Rogerio da Silva Neto ${ }^{12}$, Clovis Gomes da \\ Silva Junior ${ }^{1}$, Ig Ibert Bittencourt ${ }^{2}$
}

\author{
${ }^{1}$ Universidade de Pernambuco, Campus Garanhuns (UPE) Av. Cap. Pedro \\ Rodrigues, 105 - São José, CEP 55.294-902 - Garanhuns - PE - Brasil \\ ${ }^{2}$ Núcleo de Excelência em Tecnologias Sociais (NEES) - Instituto de Computação - \\ Universidade Federal de Alagoas (IC-UFAL) Av. Lourival Melo Mota, S/N - Tabuleiro \\ dos Martins, CEP 57072-900 - Maceió - AL - Brasil \\ \{wos, srsn, ig.ibert\}@ic.ufal.br, clovis.gomes@upe.br
}

Resumo. A avaliação de jogos educativos é uma fase importante dentro de seu processo de desenvolvimento, por possibilitar averiguar o desempenho do jogo diante de seu publico alvo. Assim este trabalho objetivou avaliar dois jogos educativos, em aspectos computacionais de interface e aspectos pedagógicos, de forma quantitativa e qualitativa. Os resultados permitiram constatar que os jogos tiveram resultados positivos em ambos os aspectos, bem como que a abordagem usada na avaliação destes jogos se mostrou eficaz diante de seus objetivos, podendo ainda ser replicada em outros contextos para avaliação de outros jogos educativos.

Abstract. The educative game evaluate is an important level in our development process, allows for ascertain game performance with target audience. Thus, this work aims evaluate two educative game in computational and pedagogical aspects, in order quantitative and qualitative. The results allowed to verify of games had positive results in both aspects, as well the approach is effective in ours aims, can be replicate in others contexts of educative game evaluate.

\section{Introdução}

Com o aumento exponencial do uso de tecnologia em todas as idades, o acesso a informações se tornou muito fácil, surgindo novas formas de agir e pensar. Um profissional capaz de se reinventar de acordo com as necessidades do momento se tornou mais desejado do que um profissional que sempre age da mesma forma, que nunca está disposto a mudar (Medeiros et al. 2012).

Com essa nova demanda do mercado, o modelo de ensino das escolas foi questionado, o padrão onde o professor somente transmite as informações e os alunos as decoram ficou defasado e desmotivador. De acordo com uma pesquisa realizada pela Fundação Getúlio Vargas em 2009 - FGV-RJ, 40\% dos jovens de 15 a 17 anos que deixam de estudar, fazem isto simplesmente porque acreditam que a escola é desinteressante. 
Assim, atualmente é necessário que os alunos aprendam a aprender, que sejam capazes de construir novos conhecimentos a partir das informações disponíveis (Medeiros et al. 2012). Os alunos da contemporaneidade estão envolvidos em ambientes colaborativos e cooperativos. Dessa maneira, cabe à escola reformular certas práticas para atingir esse novo perfil de aluno (Silva Neto et al., 2013).

Neste sentido, Sampaio e Leite (2004), afirmam que, jovens tem mais facilidade de lidar com a linguagem dos meios digitais do que a linguagem escrita. Eles se identificam com os meios eletrônicos por carregarem características semelhantes. Dentre elas, a constante presença de informações visuais e o rápido processamento de múltiplos recursos simultâneos. Visto isso, os jogos se apresentam como uma opção viável para proporcionar um ambiente lúdico e motivador aos alunos, de acordo com Sá et al., (2007), a utilização de jogos nas atividades de ensino possibilita oferecer ao aprendiz momentos lúdicos e interativos como etapas do processo de aprendizagem. Os jogos têm a capacidade de auxiliar o professor, desde que os mesmos sejam desenvolvidos e trabalhados de forma crítica, possibilitando a aprendizagem significativa do aluno (Gros, 2003).

Sendo assim, este artigo apresenta o processo de avaliação de dois jogos digitais usados no ensino de Matemática. Os jogos avaliados foram desenvolvidos por meio do processo de Virtualização de Jogos (Santos et al., 2014). O processo de avaliação destes jogos seguiu uma abordagem multi-perspectiva, buscando avaliar os aspectos computacionais de interface, bem como os aspectos pedagógicos no âmbito quantitativo e qualitativo, contando com a presença de uma equipe multidisciplinar formada por estudantes de graduação, mestrado e doutorado da Universidade de Pernambuco em parceria com a Universidade Federal de Alagoas, além de profissionais da área de Pedagogia e Psicologia.

\section{Trabalhos Relacionados}

O Trabalho de Medeiros et al. (2012) apresenta a análise da utilização de jogos eletrônicos na educação como auxílio ao processo de aprendizado, é exposto uma revisão de literatura sobre os benefícios dos jogos educativos e algumas observações importantes na aplicação de jogos eletrônicos nas escolas, por fim, é desenvolvido uma proposta para avaliação de jogos eletrônicos educativos.

No trabalho de Dias et al. (2013) é apresentado um modelo de avaliação de jogos educativos baseado em "perspectivas". Esta proposta foi baseada na técnica de leitura de software PBR (Perspective Based Reading - Leitura Baseada em Perspectivas). Neste modelo, os avaliadores assumem diferentes perspectivas com o intuito de melhor avaliar o jogo educacional e entende-se que com a atenção focada para uma determinada área, produzem-se resultados mais consistentes. $\mathrm{O}$ modelo apresenta $\mathrm{o}$ enquadramento de quatro perspectivas: a) Especialista, na área cujo conhecimento pedagógico se insere; b) Sujeitos, para os quais o jogo é desenvolvido; c) Especialista em Jogos (tem experiência e joga) e d) Empreendedor, na área de jogos comerciais.

O mesmo se verifica no trabalho de Savi et al. (2010) que propõe um modelo para a avaliação de jogos educacionais baseado no modelo de avaliação de programas de 
treinamento de Kirkpatrick, nas estratégias motivacionais do modelo ARCS de Keller, na área de experiência do usuário e na taxonomia de objetivos educacionais de Bloom.

Neste sentido, este trabalho tem como diferencial o fato de apresentar a avaliação de dois jogos, levando em consideração as perspectivas do modelo GameFlow, Lori $e$ Kirkpatrick, focado em perspectiva qualitativa e quantitativa.

\section{Avaliação de Jogos Educativos}

A avaliação de um jogo educativo deve ser feita com metodologias específicas, pois a incorporação desses aplicativos só se justifica quando possibilita um avanço qualitativo nos processos de ensino-aprendizagem (Gladcheff et al., 2011).

Dentre as metodologias, modelos e técnicas de avaliação de jogos se destacam LORI (Learning Object Review Instrument) e GameFlow.

A LORI foi desenvolvida como um guia de avaliação de objetos de aprendizagem. Esta avaliação é composta por nove itens. (1) Qualidade do Conteúdo: apresentação equilibrada das ideias com nível apropriado de detalhes; (2) Alinhamento da Aprendizagem: Alinhamento entre as metas de aprendizagem, atividades, avaliações e características dos alunos; (3) Feedback e Adaptação: Conteúdo adaptável e feedback de acordo com as características do aluno; (4) Motivação: Capacidade de motivar o interesse; (5) Design da Apresentação: Referente à informação visual; (6) Usabilidade: Facilidade de navegação e qualidade dos recursos de ajuda da interface; (7) Acessibilidade: Facilidade do acesso independente de plataforma; (8) Reusabilidade: Habilidade para usar em diferentes contextos de aprendizagem; (9) Aderência a padrões: Adesão às normas e especificações internacionais (Medeiros et al., 2012)

O GameFlow por sua vez, avalia o quão prazeroso é o jogo para o jogador. Essa avaliação é composta por alguns critérios Concentração: Jogos devem exigir concentração; Desafio: Jogos devem ser desafiadores e corresponderem ao nível de habilidade do jogador; Habilidade do Jogador: Jogos devem apoiar o desenvolvimento da habilidade do jogador; Controle: O jogador deve ter sensação de controle sobre suas ações no jogo; Objetivos Claros: Jogos devem fornecer metas claras ao jogador; Feedback: O jogador deve receber feedback adequado em momentos apropriados; Imersão: O jogador deve ter envolvimento profundo; e Interação Social: Jogos devem apoiar e criar oportunidades de interação social.

Além dessas metodologias observou-se que o modelo de avaliação de treinamentos de Kirkpatrick (1994) pode ser utilizado para detectar o quanto a aplicação dos jogos é eficiente, ele é dividido em quatro níveis. Cada nível tem sua importância e, conforme se passa de um nível para outro seguinte, o processo se torna mais complexo e demorado, porém fornece resultados mais valiosos. Os níveis são:

(1) Reação: onde se mede a satisfação e valor percebido do treinamento pelos participantes.

(2) Aprendizagem: levanta o quanto os participantes podem mudar de atitude, ampliar seus conhecimentos e/ou habilidades; 
(3) Comportamento: identifica o quanto os participantes mudaram seu comportamento em decorrência do que foi aprendido;

(4) Resultados: identifica os ganhos obtidos no treinamento.

\section{Jogos Avaliados}

Os jogos avaliados foram desenvolvidos por uma equipe multidisciplinar, com a participação de profissionais da Psicologia, Pedagogia, Matemática e Computação, por meio do processo de Virtualização de Jogos, processo que busca criar versões digitais para jogos tradicionais, outrora usados de forma positiva no ensino e algum conteúdo, objetivando manter os aspectos Pedagógicos e Psicopedagógicos da versão tradicional do jogo, ao mesmo tempo em que estejam atrelados as mecânicas de jogos digitais contemporâneos (Santos et al. (2014), Santos e Silva Junior (2014) e Cassimiri (2009)). Os jogos ora avaliados abordam conteúdos específicos da disciplina de Matemática.

\subsection{Jogo Conquistando com Resto}

O jogo consiste em um tabuleiro com 48 casas, numeradas de forma não sequencial. Os jogadores começam o jogo na casa 43 (primeira casa do tabuleiro) e jogam sequencialmente um dado em formato de cubo (um jogador por vez) dividindo o valor da casa em que se encontra (incialmente casa 43) pelo valor que for obtido no dado, em seguida avança exatamente o quantitativo de casas correspondente ao resto desta divisão.

Por exemplo: caso o jogador esteja na casa 43 e no dado seja sorteado 4, divide-se 43 (valor da casa) por 4 (valor do dado) e avança a quantidade de casas correspondente ao resto dessa divisão, que é 3. Neste caso o jogador iria para a casa 15 (terceira casa do tabuleiro), vence o jogo quem chegar à casa 96 (ultima casa do tabuleiro) primeiro, como pode se observado na Figura 1 que mostra o jogo em sua versão tradicional (Figura parte a).

A versão digital deste jogo é composta por quatro telas que são apresentadas seguir: (i) Tela Início: Na tela início os jogadores tem sua primeira interação com o jogo, bem como podem escolher o percurso inicial que irão percorrer no jogo. (ii) Tela Créditos: Tela que apresenta as informações dos desenvolvedores da versão digital do jogo. (iii) Tela Regras: Nesta tela são apresentadas as regras do jogo, bem como exemplos que devem auxiliar os jogadores na execução do mesmo. (iv) Tela Jogo: Nesta tela é apresentado o jogo. Esta assume fundamental importância para o mesmo, pois é nela que se encontra o objeto principal do software desenvolvido, "o jogo". A Figura 1 (parte $b$ ) mostra as telas do jogo em sua versão digital.

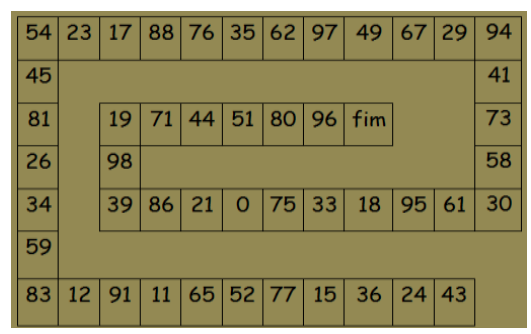

Parte a

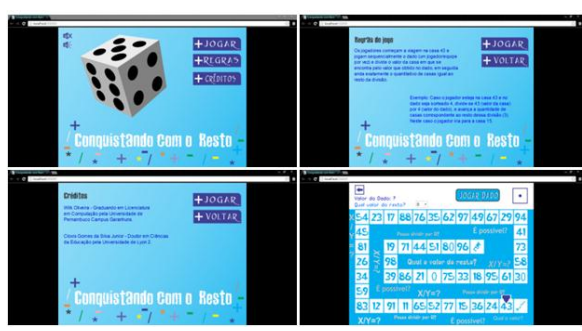

Parte $b$ 


\section{Figura 1: Conquistando com Resto}

\subsection{Jogo Desafios com Palitos}

O jogo "Desafios com Palitos" trata-se de um tradicional jogo, usado como instrumento de ensino para uma serie de conceitos da disciplina da Matemática, dependendo de como seja usado pelo professor, o jogo pode abordar diferentes tipos de conteúdos, como Algarismos Romanos, Conversão de Valores, Raciocínio Logico, entre outros. Este jogo pode ser jogado de forma individual, em duplas, ou mesmo em equipes de jogadores. A Figura 2 (parte $a$ ) apresenta o mesmo em seu formato tradicional/manual.

Para a versão digital deste jogo, foram escolhidos dez desafios diferentes, envolvendo diferentes conteúdos como: Algoritmos Romanos, Conversão de Valores e Raciocínio Logico, entre outros. A Figura 2 (parte b) mostra a tela inicial do jogo, bem como as fases 6 e 8 que abordam, respectivamente, Raciocínio Logico e Trigonometria Básica.

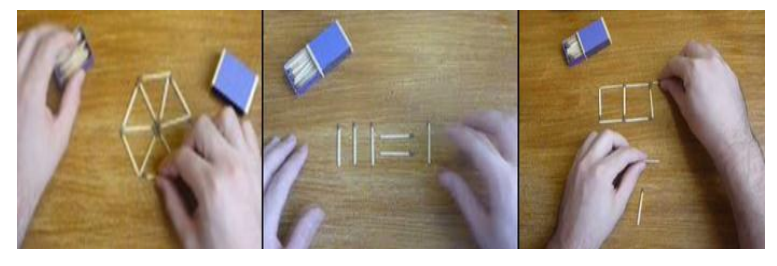

Parte $a^{l}$
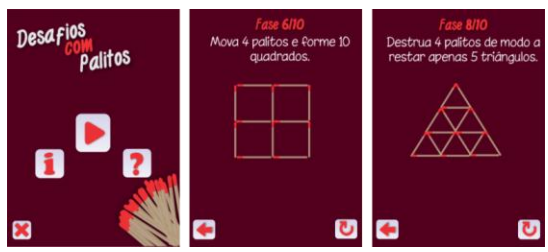

Parte b

Figura 2: Jogo Desafios com Palitos

\section{Avaliação}

De acordo com de França e Silva (2014) a maioria dos trabalhos que apresentam algum tipo de avaliação de softwares educativos, independente, de tratar-se de avaliação de jogos ou de outros tipos de software educativos, normalmente tratam apenas da avaliação computacional de interface em detrimento a avaliação pedagógica, ou da avaliação pedagógica, em detrimento a avaliação computacional de interface, em uma única perspectiva.

Assim, este trabalho, preocupou-se em realizar uma avaliação multiperspectiva de maneira a englobar aspectos computacionais de interface e aspectos pedagógicos, seguindo uma abordagem baseada em três diferentes abordagens para a avaliação de jogos (LORI, GameFlow e modelo de Kirkpatrick). Para a realização da avaliação de interface do jogo, os estudantes responderam a uma serie de questões assertivas. Cada questão (mostardas nos quadros um e dois) foi formulada a fim de chegar a conclusões de acordo com as abordagens anteriormente mencionadas, ou seja, as questões foram definidas de acordo com as abordagens LORI, GameFlow, além do modelo de Kirkpatrick.

Optou-se por realizar esta avaliação de forma quantitativa, fazendo uso da Escala de Likert, que em conformidade com Santos et al. (2014) permite mostrar qual o

\footnotetext{
${ }^{1}$ Imagens retiradas a partir de capturas de tela do vídeo contido no seguinte link: http://migre.me/p2fB6
} 
grau de concordância e/ou discordância do usuário em relação aos elementos funcionais de determinado objeto.

$\mathrm{Na}$ avaliação pedagógica, cada estudante recebeu uma folha de rascunho, de modo que pudesse a usar, sempre que necessário, para ajudar na resolução dos desafios do jogo. Esta folha foi posteriormente analisada pelo professor de Matemática, que por meio da visualização dos rascunhos, pode realizar observações quanto ao jogo e sua eficácia. Além disto, a avaliação ocorreu por meio da observação dos demais profissionais que acompanharam esta avaliação.

A seleção de estudantes para realizar a avaliação dos jogos, ocorreu de forma aleatória, selecionando um grupo de dez estudantes com idades entre dez e doze anos, integrantes da $5^{\mathrm{a}}$ série $/ 6^{\circ}$ ano, de uma escola pública estadual, situada no Agreste do estado de Pernambuco. A escolha de um número reduzido de estudantes se deu em função de assumirmos que este número aumenta a qualidade de avaliação qualitativa, por permitir uma investigação individual mais aprofundada por parte dos profissionais envolvidos na pesquisa, ao mesmo tempo, que representa um grupo focal suficiente para obtenção de dados na avaliação quantitativa.

Colaboraram com esta etapa do trabalho, um professor de Matemática do ensino básico, um professor doutor em Matemática e uma profissional da área de Psicologia, responsáveis por analisar as ações dos estudantes durante o processo de jogo. A quantidade de estudantes que participaram avaliação possibilitou uma análise mais eficaz dos principais aspetos levados em consideração na avaliação.

\subsection{Conquistando com Resto: Avaliação Computacional de Interface}

$\mathrm{Na}$ avaliação computacional de interface deste jogo, os estudantes responderam um total de oito questões. O Quadro 1 mostra as assertivas apresentadas aos estudantes e os resultados obtidos. As opções disponibilizadas para cada uma das questões foram: Concordo Fortemente (CF); Concordo (C); Indeciso (I); Discordo (D); Discordo Fortemente (DF).

\begin{tabular}{|c|c|c|c|c|c|}
\hline \multicolumn{6}{|c|}{ Resultados Quantitativos da Interface } \\
\hline Assertiva/Opção & $\mathrm{CF}$ & $\mathrm{C}$ & $\mathrm{I}$ & $\mathrm{D}$ & $\mathrm{DF}$ \\
\hline O jogo reconhece meus toques no mouse e teclado. & $20 \%$ & $60 \%$ & $10 \%$ & $10 \%$ & $0 \%$ \\
\hline As cores do jogo são agradáveis. & $10 \%$ & $60 \%$ & $30 \%$ & $0 \%$ & $0 \%$ \\
\hline Entendi o que cada ícone representa. & $40 \%$ & $20 \%$ & $30 \%$ & $10 \%$ & $0 \%$ \\
\hline A interface possui informações de fácil entendimento. & $20 \%$ & $40 \%$ & $40 \%$ & $0 \%$ & $0 \%$ \\
\hline Entendi rapidamente o que deveria fazer no jogo. & $20 \%$ & $20 \%$ & $50 \%$ & $10 \%$ & $0 \%$ \\
\hline $\begin{array}{l}\text { É mais fácil aprender Matemática com o jogo Conquistando } \\
\text { com o Resto. }\end{array}$ & $50 \%$ & $50 \%$ & $0 \%$ & $0 \%$ & $0 \%$ \\
\hline O jogo é motivador e me deixam com vontade de continuar. & $50 \%$ & $40 \%$ & $10 \%$ & $0 \%$ & $0 \%$ \\
\hline $\begin{array}{l}\text { Instalaria o jogo no meu computador ou dispositivo móvel e } \\
\text { recomendaria a um amigo. }\end{array}$ & $70 \%$ & $30 \%$ & $0 \%$ & $0 \%$ & $0 \%$ \\
\hline
\end{tabular}

\section{Quadro 1: Conquistando com o Resto (avaliação quantitativa de interface)}

Os resultados obtidos nesta etapa da avaliação oportunizaram perceber que o jogo reconhece os movimentos e toques realizados pelos jogadores, tornando fácil a realização de jogadas, bem como a aceitação dos estudantes em relação às cores do jogo, torando agradável o ato de jogar e, por conseguinte, corroborando para que o mesmo possa permanecer por mais tempo no jogo. 
O entendimento por parte dos jogadores no que cerne os ícones e representações presentes no jogo, bem com a presença de poucos itens e informações de interface foi outro fato que permitiu aferir a boa jogabilidade presente no jogo. A maioria dos jogadores não compreendeu de forma rápida o que deveria fazer no jogo, esta informação nos permitiu indagar se o problema relacionado a esta percepção estava no fato do jogo não dispor de mecanismos que permitissem esta compreensão por parte dos estudantes, ou se esta problemática estava ligada aos conhecimentos prévios dos estudantes em relação ao conteúdo abordado, visto que se pôde observar que o jogo apresenta poucas informações de interface e cores agradáveis, proporcionado fácil entendimento do mesmo.

Percebeu-se ainda, de acordo com os dados desta avaliação que a maioria absoluta dos estudantes, concordou que foi mais fácil compreender os assuntos de Matemática com o uso do jogo, bem como acreditam que o mesmo é motivador e os instigam a permanecer por mais tempo no jogo. A maioria absoluta concordou também que instalaria o jogo em seu dispositivo móvel, ou em seu computador, demostrando que os mesmos se mostraram satisfeitos com o jogo, motivados para continuar a jogar e dispostos a continuar a aprender os conceitos apresentados no jogo.

\subsubsection{Conquistando com Resto: Avaliação Pedagógica}

De acordo com o professor que realizou a análise nos rascunhos, a maioria dos estudantes, ao se deparar com um cálculo que resultasse em um número decimal, apresentaram dificuldades em utilizar o resto da divisão, aferindo que os mesmos apresentam dificuldades para resolver problemas com a operação básica de divisão, sendo assim, estes estudantes buscaram fazer uso da operação inversa da divisão (multiplicação) para chegar à resolução da questão.

Pode-se perceber ainda, que a maioria dos discentes notou que seria difícil encontrar um número no dado, que apresentasse um divisor não exato para os números 24 e 36, fato que chamou a atenção de alguns destes estudantes e os fizeram questionar este fato. Tal acontecimento, segundo o professor é um fato que permite ao docente esclarecer uma serie de conceitos matemáticos, quando questionado em sala de aula.

O mesmo aconteceu em relação ao número zero, os estudantes chegaram a testar todas as possibilidades de divisão com relação a este número, para poder observar que é impossível a divisão por zero, somente depois de realizar todos os testes os discentes começaram a questionar este fato. Através desta percepção, foi possível diagnosticar que o jogo conseguiu abordar uma regra fundamental da Matemática básica, cumprindo assim com seus objetivos pedagógicos abordados desde sua versão tradicional, a Figura 3 mostra os rascunhos de um estudante, que deixa claro as observações anteriormente descritas. 


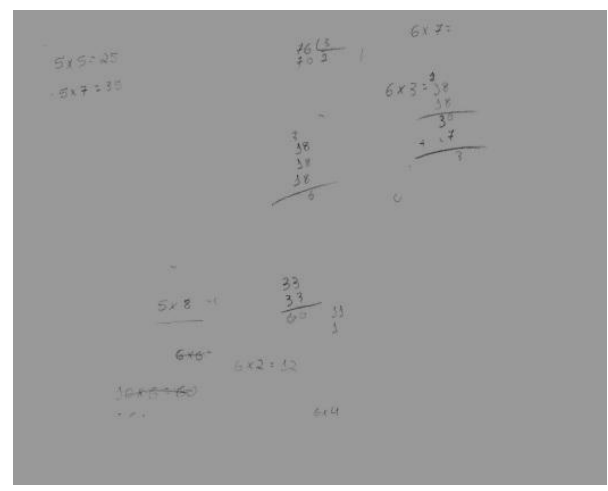

Figura 3: Conquistando com Resto: folha de rascunho

\subsection{Desafios com Palitos: Avaliação Computacional de Interface}

Para a avaliação computacional de interface deste jogo, foram formuladas sete questões. O Quadro 2 mostra as assertivas apresentadas aos estudantes e os resultados obtidos. Para cada assertiva foram apresentadas as seguintes opções. Concordo Fortemente (CF); Concordo (C); Indeciso (I); Discordo (D); Discordo Fortemente (DF).

\begin{tabular}{|c|c|c|c|c|c|}
\hline \multicolumn{6}{|c|}{ Resultados Quantitativos da Interface } \\
\hline Assertiva/ Opção & $\mathrm{CF}$ & $\mathrm{C}$ & I & $\mathrm{D}$ & DF \\
\hline $\begin{array}{l}\text { O jogo reconhece meus toques na tela e movimenta } \\
\text { corretamente os palitos. }\end{array}$ & $35 \%$ & $55 \%$ & $10 \%$ & $0 \%$ & $0 \%$ \\
\hline As cores do jogo são agradáveis. & $40 \%$ & $20 \%$ & $20 \%$ & $20 \%$ & $0 \%$ \\
\hline Entendi o que cada ícone representa. & $45 \%$ & $25 \%$ & $20 \%$ & $10 \%$ & $0 \%$ \\
\hline $\begin{array}{l}\text { A interface possui poucas informações e as mesmas } \\
\text { são de fácil entendimento. }\end{array}$ & $25 \%$ & $55 \%$ & $20 \%$ & $0 \%$ & $0 \%$ \\
\hline $\begin{array}{l}\text { Entendi rapidamente o que deveria fazer nos desafios } \\
\text { do jogo. }\end{array}$ & $30 \%$ & $30 \%$ & $10 \%$ & $20 \%$ & $10 \%$ \\
\hline $\begin{array}{l}\text { Os desafios do jogo são motivadores e me deixa com } \\
\text { vontade de continuar. }\end{array}$ & $45 \%$ & $45 \%$ & $10 \%$ & $0 \%$ & $0 \%$ \\
\hline Me senti satisfeito ao conseguir resolver os desafios. & $45 \%$ & $35 \%$ & $10 \%$ & $10 \%$ & $0 \%$ \\
\hline
\end{tabular}

\section{Quadro 2: Conquistando com o Resto (avaliação quantitativa de interface)}

A avaliação quantitativa de interface do jogo "Desafios com Palitos" oportunizou perceber-se que o jogo reconheceu os toques de entradas dos jogadores, fator importante, especialmente por se tratar do jogo mobile que por vezes pode ser jogado em dispositivos com telas de tamanho pequeno. Observou-se também que a maioria dos estudantes agradou-se das cores do jogo, bem como tiveram fácil entendimento dos ícones de representação do jogo.

A maioria também concordou que o jogo dispôs de poucas informações, e as informações contidas são de fácil entendimento, esta constatação assume importante valor por se tratar de um jogo que aborda diferentes conteúdos matemáticos, e, por conseguinte pode ser jogado por diferentes públicos. Ademais, os estudantes afirmaram por meio do questionário que se sentiram motivados com o jogo, ao mesmo tempo em que ficaram satisfeitos com os desafios enfrentados ao longo do jogo. Esta ultima constatação assume imensa importância, pelo fato de ser sabido que é de fundamental 
importância que os jogos transmitam aos jogadores o sentimento de motivação no decorrer de suas jogadas.

\subsubsection{Desafios com Palitos: Avaliação Pedagógica}

Notou-se que neste jogo, o uso da folha de rascunho foi relativamente menor em relação ao jogo anterior, neste caso, os estudantes conseguiram resolver a maioria dos desafios sem o auxilio da folha de rascunho. De acordo com os profissionais que acompanharam os testes, tal fato ocorre, por neste os desafios não envolverem cálculos matemáticos, tal ocorrência é comprovada pelo fato ocorrido de que o uso da folha de rascunho foi maior, nas fases que envolviam cálculos (mesmo que de forma indireta), por exemplo, nas fases 3 e 5 que tem como desafios intrínsecos, problemas envolvendo Algarismos Romanos.

Ainda neste contexto, observou-se que os estudantes, por vezes, tinham lapsos de entendimento de certos assuntos matemáticos, como em alguns casos onde estes estudantes observavam que determinados assuntos do jogo, poderiam ser usados em sala de aula no intuito de resolver certos assuntos abordados nas aulas tradicionais pelos seus professores, fato que permite diagnosticar que o jogo cumpre com o seu objetivo pedagógico de abordar de forma implícita, determinados conceitos matemáticos, sem que o mesmo perca sua jogabilidade.

\section{Considerações Finais}

De acordo com Dias et al., (2013) e Gladcheff et al., (2011), é de extrema importância avaliar os jogos educativos em aspectos computacionais de interface e aspectos pedagógicos, de maneira que seja possível validar a competência destes jogos diante de seus objetivos, ainda em conformidade com França e Silva (2014), que afirmam que a avaliação de jogos tem se preocupado somente com uma avaliação voltada a interface, ou apenas voltada aos aspectos pedagógico, este trabalho realizou uma avaliação em dois jogos educativos para o ensino de Matemática diante de ambas as perspectivas.

A avaliação realizada permitiu perceber que ambos os jogos tiveram resultados positivos diante do cenário em que foram avaliados, na maioria dos princípios requeridos pelas três abordagens usadas, sendo necessário, contudo, a implementação de modulo de interação nos jogos, de modo a atingir o requisito da abordagem game flow. Neste sentido, o processo de avaliação adotado para estes jogos pode ser replicado ou adaptado para outros jogos educativos, mesmo que estes sejam de domínios diferentes.

Desafia-se como trabalhos futuros a avaliação dos jogos em diferentes cenários, bem como submeter outros jogos desenvolvidos por este grupo de pesquisa ao mesmo processo de avaliação. Destaca-se ainda, que o processo de avaliação adotado pode ser replicado para jogos educativos de diferentes contextos educativos, mediante adaptações pontuais.

\section{Referências}

Carissimi, A. (2009) "Virtualização: Princípios básicos e aplicações”. Minicurso da 9" Escola Regional de Alto Desempenho-ERAD, p. 39-69. 
Cybis, W., Betiol, A. H.; Faust, R. (2007) "Ergonomia e usabilidade: conhecimentos, métodos e aplicações". Novatec Editora.

de França, R. S., \& da Silva, A. C. B. (2014) "Avaliação de softwares educativos para o ensino de Língua Portuguesa". Revista Brasileira de Informática na Educação (RBIE), 22(03), 23.

Dias, J., M.; Nascimento, F.,S.; hetkowski, T., M.; Brandao, I.; Pereira, T., R., D., S. (2013) "Avaliação de jogos educacionais digitais baseada em Perspectivas Uma experiência através do Jogo-simulador Kimera". In: Anais do Simpósio Brasileiro de Jogos e Entretenimento Digital (SBGames).

Gladcheff, A., P.; Zuffi, E., M.; Silva, M., D. (2011) “Um Instrumento para Avaliação da Qualidade de Softwares Educacionais de Matemática para o Ensino Fundamental”. In: Anais do Workshop de Informática na Escola (WIE), FortalezaCE.

Gros, Begoña. (2003) "The impact of digital games in education”. First Monday, v.8, n.7, jul. disponivel em: http://www.firstmonday.org/issues/issue8_7/xyzgros/index.html. Acesso em: 22 out. (2007).

Kirkpatrick, D., L. (1994) "Evaluating Training Programs - The Four Levels". Berrett-Koehler Publishers, Inc.

Medeiros, M., O.; Schimiguel, J. (2012) "Uma Abordagem Para Avaliação De Jogos Educativos: Ênfase No Ensino Fundamental". Revista Novas Tecnologias na Educação (RENOTE), v. 10, n. 3, 2012.

Sá, E., J., V; Teixeira, J.,S.,F; Fernandes, C.,T. (2007) "Design de atividades de aprendizagem que usam Jogos como princípio para Cooperação". In: Anais Simpósio Brasileiro de Informática na Educação (SBIE), São Paulo - SP, Brasil

Sampaio, M., N.; Leite, L., S. (2004) “Alfabetização tecnológica do professor”. 4 ed. Petrópolis: Vozes.

Santos, W. O.; da Silva, A. P.; Silva Junior, C. G. (2014) "Conquistando com o Resto: Virtualização de um Jogo para o Ensino de Matemática”. In: Anais do Simpósio Brasileiro de Informática na Educação (SBIE). p. 317-321.

Santos, W. O.; Silva Junior, C. G. (2014) "Uso de Jogos no ensino da Matemática: Uma análise entre os jogos tradicionais e os jogos digitais, baseada em pesquisa e mapeamento dos materiais encontrados na Web”. In: X Seminário Jogos Eletrônicos, Educação e Comunicação. Salvador - BA.

Savi, R.; Von Wangenheim, C. G.; Ulbricht, V.; Vanzin, T. (2010). "Proposta de um modelo de avaliação de jogos educacionais". In: Revista Novas Tecnologias na Educação (RENOTE).

Silva Neto, S. R., Santos, H. R. M., de Souza, A. A., \& dos Santos, W. O. (2013). "Jogos Educacionais como Ferramenta de Auxílio em Sala de Aula". In: Anais do Workshop de Informática na Escola (WIE) Campinas-SP. 